University of Nebraska - Lincoln

DigitalCommons@University of Nebraska - Lincoln

USDA National Wildlife Research Center - Staff Publications
U.S. Department of Agriculture: Animal and Plant Health Inspection Service

2016

\title{
Evaluation of estimation quality of a general paradigm for indexing animal abundance when observations are counts
}

\author{
Benjamin Shulman \\ University of Colorado Denver Anschutz Medical Campus \\ Brandie D. Wagner \\ University of Colorado Denver Anschutz Medical Campus \\ Gary K. Grunwald \\ University of Colorado Denver Anschutz Medical Campus \\ Richard M. Engeman \\ USDA-APHIS-Wildlife Services, s_r100@yahoo.com
}

Follow this and additional works at: https://digitalcommons.unl.edu/icwdm_usdanwrc

Part of the Life Sciences Commons

Shulman, Benjamin; Wagner, Brandie D.; Grunwald, Gary K.; and Engeman, Richard M., "Evaluation of estimation quality of a general paradigm for indexing animal abundance when observations are counts" (2016). USDA National Wildlife Research Center - Staff Publications. 1792.

https://digitalcommons.unl.edu/icwdm_usdanwrc/1792

This Article is brought to you for free and open access by the U.S. Department of Agriculture: Animal and Plant Health Inspection Service at DigitalCommons@University of Nebraska - Lincoln. It has been accepted for inclusion in USDA National Wildlife Research Center - Staff Publications by an authorized administrator of DigitalCommons@University of Nebraska - Lincoln. 


\title{
Evaluation of estimation quality of a general paradigm for indexing animal abundance when observations are counts
}

\author{
Benjamin Shulman a,1, Brandie D. Wagner ${ }^{\mathrm{a}}$, Gary K. Grunwald ${ }^{\mathrm{a}}$, Richard M. Engeman ${ }^{\mathrm{b}, *}$ \\ a Department of Biostatistics and Informatics, University of Colorado Denver Anschutz Medical Campus, Box B-119, 13001 E. 17th Place, Aurora, CO 80045, USA \\ ${ }^{\mathrm{b}}$ National Wildlife Research Center, 4101 LaPorte Avenue, Fort Collins, CO 80521-2154, USA
}

\section{A R T I C L E I N F O}

Article history:

Received 30 December 2015

Received in revised form 19 February 2016

Accepted 22 February 2016

Available online 2 March 2016

\section{Keywords:}

Animal surveys

Negative binomial distribution

Poisson distribution

Population index

Relative abundance

\begin{abstract}
A B S T R A C T
Relative abundance indices are widely applied to monitor wildlife populations. A general indexing paradigm was developed for structuring data collection and validly conducting analyses. This approach is applicable for many observation metrics, with observations made at stations through the area of interest and repeated over several days. The variance formula for the general index was derived using a linear mixed model, with statistical tests and confidence intervals constructed assuming Gaussian-distributed observations. However, many observation methods, like intrusions to track plots or camera traps, involve counts with many zeroes, producing Poissonlike observations. To fill this inferential gap between Gaussian analytical assumptions and Poisson-distributed data we evaluated, via a broad Monte Carlo simulation study, variance estimation and confidence interval coverage when Gaussian statistical inference is applied to data generated from a Poisson distribution. The mixed effects linear model assuming Gaussian observations performed well in estimating variances and confidence intervals when simulated Poisson data were in the range found in field studies (88-96\% confidence interval coverage). Estimation improved by increasing the number of observation days. Confidence interval coverage rates performed very well (even with few observation days) when day-to-day variability was small, while effective estimation resulted for a great range in station-to-station variability. These results provide a foundational basis for applying the general indexing paradigm to count data, strengthen the generality of the approach, provide valuable information for study design, and should reassure practitioners about the validity of their analytical inferences when using count data.
\end{abstract}

Published by Elsevier B.V.

\section{Introduction}

A quantitative means to track animal abundance is an essential component of wildlife management and ecological and environmental study, with its importance well-portrayed by the old adage, "If you can't monitor it, you can't manage it." Practical in-field observation methods for assessing relative abundance of single species or multiple wildlife species simultaneously provides a broad ability and efficiency for managers and researchers to infer and compare population differences, trends, and changes over time or between geographical areas (e.g. Caughley, 1977; Engeman, 2005). Due to their practicality, index methods quantifying relative population abundances play pivotal roles in addressing questions about, and monitoring changes in wildlife populations (Caughley, 1977; Engeman, 2005). Indices are observation methods combined with analytical procedures that produce a statistic that reflects relative abundance of a population (Caughley, 1977; Engeman, 2005). Despite the many potential benefits offered, indexing

\footnotetext{
* Corresponding author at: National Wildlife Research Center, 4101 LaPorte Avenue, Fort Collins, CO 80521-2154, USA.

E-mail address: richard.m.engeman@aphis.usda.gov (R.M. Engeman).

1 Now at: EDUCAUSE, 282 Century Place, Suite 5000, Louisville, CO 80027, USA.
}

has been both criticized (Anderson, 2001) and praised (e.g., Caughley, 1977) as an inferential approach concerning animal abundance dynamics. However, when suitable statistical design and analysis principles are applied in the development of indexing procedures, the criticisms become unfounded (Engeman, 2003, 2005). To the end of obtaining observations and calculating abundance indices within the context of valid statistical theory, Engeman (2005) presented a general observation structure and analytical methods which are applicable to many forms of field observations for creating indices of abundance. In that general paradigm, observations are made at stations located throughout the area of interest, with observations being made at each station on multiple occasions for each indexing session. A wide variety of observation methods for many animal species can fit into this format including tracking rates, camera trap data, spotlight counts, pellet counts, capture rates, bait consumption, or visual observations, among many other possibilities (Engeman, 2005).

Engeman (2005) quantitatively described the general index (GI) using a linear mixed model and derived a corresponding formula for its variance and applied traditional Gaussian-based (normal distribution based) methods for confidence interval calculations, thereby providing an efficient way for investigators to make comparisons such as between indices from different sites at the same time(s) or between 
years at the same site. Thus, observations are implicitly assumed to follow a Gaussian distribution in construction of statistical tests and confidence intervals incorporating the variance calculation for GI. Making continuous measurements at each station suits well the application of Gaussian-based statistical inference about index values, whereas binary (presence-absence) measurements have been well-documented to produce inferior results (e.g. Allen et al., 1996, 2011; Engeman, 2005; Engeman and Allen, 2000). Alternatively, it is very common for the observations made at each station to involve a count. The most common examples of count observations include the number of intrusions (number of sets of tracks) by a species into a tracking plot, the number of individuals (or intrusions) of a species photographed at a camera station, and the number of each species visually observed at an observation station in a fixed amount of time. Many examples (with citations) of the types of observation stations and observation methods that result in count data are given in Table 1.

For many common situations (such as the above-mentioned tracking plot intrusions or photographs from camera traps), the observation at each station usually involves a small count (typically $\leq 10$ ) with a high frequency of zeroes, not uncommonly more than half of all observations (see citations in Table 1). Such data clearly are not normally distributed, which calls into question the validity of applying the methods based on the normality assumption to calculate confidence intervals and comparative statistical tests, although inference validity was assumed legitimate under the Central Limit Theorem because the index form is calculated as a mean of means. Nonetheless, this indexing method is in widespread use with count observations and has been for many years. For example, when used as a passive tracking index (PTI), the GI has been recommended, and even standardized as the monitoring technique for assessing various wildlife populations (Allen et al., 2012; Engeman et al., 2013; Mitchell and Balogh, 2007). Thus, it is vital to evaluate GI performance from a statistical theory and empirical estimation standpoint using the type of count data to which it is often applied.

We performed a Monte Carlo simulation study to generate small count data from the Poisson distribution and evaluated the effectiveness of the linear mixed model and Gaussian-based inference for estimating the variance and confidence interval using the GI. To do this, formulae for the mean and variance of $G I$ were first derived when observations follow a Poisson model with over-dispersion as described in Methods below. Observations were then simulated, allowing for over-dispersion and crossed random effects for station and day. Finally, the variance of the index was estimated using the existing linear mixed model methodology under the assumption of normality and the resulting estimates were compared to the known (pre-specified input) variances from which the data were generated, and the coverage of $95 \% \mathrm{CIs}$ under the assumption of normality was also assessed.

\section{Methods}

\subsection{Normal mixed model}

First we consider the data structure and accompanying mixed model upon which the GI calculations were based (Engeman, 2005). For $S$ stations observed over $D$ days, let $Y_{i j}$ represent the count (e.g., number of sets of tracks) observed for the ith station on the $j$ th day. GI then is the mean of the $d$ daily means; each daily mean is the mean of all stations observed on day $j$. Note that the number of stations observed may vary from day to day due to missing data.

Engeman (2005) defined a linear mixed model to describe the $Y_{i j}$ :

$Y_{i j}=\mu+s_{i}+d_{j}+e_{i j}$

In this model, $e_{i j} \sim N\left(0, \sigma_{\varepsilon}^{2}\right)$ represents random error associated with each station on each day; $d_{j} \sim N\left(0, \sigma_{d}^{2}\right)$ is a random effect associated with the $j$ th day on which an observation was made; $j=1,2,3, \ldots D$, where $D$ is the number of days on which the stations are monitored. $s_{i} \sim N\left(0, \sigma_{s}^{2}\right)$ is a random effect associated with the $i$ th station; $i=$ $1,2,3, \ldots S_{j} \leq S$, where $S_{j}$ is the number of stations observed on day $j$ from a total of $S$ available stations. Because each station is observed on each day (barring missing data), the random effects for station and day, $s_{i}$ and $d_{j}$, are defined as "crossed" random effects. We note that this crossed random effect observation pattern would be distinctly different from random effects arising from each day having a unique set of stations observed, which are commonly referred to as "nested" random effects (Fitzmaurice et al., 2008). The crossed random effect linear mixed model (1) is the one on which the current variance estimation method is based, and is the model evaluated in this simulation study.

\subsection{Poisson mixed model}

An alternative, generalized linear mixed model based on a Poisson distribution with over-dispersion was used to simulate the correlated

Table 1

Examples demonstrating the diversity of animals and observation procedures encompassed by the general indexing paradigm where observations typically are counts.

\begin{tabular}{|c|c|c|c|}
\hline $\begin{array}{l}\text { Observation station } \\
\text { example }\end{array}$ & Potential count measurement & $\begin{array}{l}\text { Examples of potential species } \\
\text { observed }\end{array}$ & Example citations for the type of station or measurement \\
\hline Tracking plots & $\begin{array}{l}\text { Number of track intrusions } \\
\text { by each species into plot }\end{array}$ & $\begin{array}{l}\text { medium to large mammals; } \\
\text { e.g., } \\
\text { carnivores, ungulates, } \\
\text { macropods, mesopredators }\end{array}$ & $\begin{array}{l}\text { Allen et al. (1996); Engeman and Evangelista (2006); } \\
\text { Engeman et al. (2000, 2003); Mahon et al. (1998) }\end{array}$ \\
\hline Camera & Number photographed & Most terrestrial wildlife species & $\begin{array}{l}\text { Bengsen et al. (2011); De Bondi et al. (2010); } \\
\text { Meek et al. (2012) }\end{array}$ \\
\hline $\begin{array}{l}\text { Road counts (normal light, } \\
\text { night vision, thermal } \\
\text { imaging) }\end{array}$ & $\begin{array}{l}\text { Number of each species counted } \\
\text { in each road segment }\end{array}$ & Many mammal and bird species & $\begin{array}{l}\text { Allison and Destefano (2006); Choquenot et al. (1990); } \\
\text { Focardi et al. (2001); McCafferty (2007); } \\
\text { Twigg et al. (1998) }\end{array}$ \\
\hline $\begin{array}{l}\text { Aerial surveys (normal light, } \\
\text { thermal imaging) }\end{array}$ & $\begin{array}{l}\text { Number counted in each aerial } \\
\text { transect }\end{array}$ & Larger mammals & Beard (1999); Caughley (1977) \\
\hline Mound count plot & $\begin{array}{l}\text { Number of mounds or } \\
\text { feeder plugs in plot }\end{array}$ & pocket gophers & $\begin{array}{l}\text { Anthony and Barnes (1983); } \\
\text { Engeman et al. (1993); Reid et al. (1966) }\end{array}$ \\
\hline Visual observation sites & $\begin{array}{l}\text { Number seen within a } \\
\text { fixed time and distance }\end{array}$ & $\begin{array}{l}\text { birds, ground squirrels, } \\
\text { muskrats }\end{array}$ & $\begin{array}{l}\text { Fagerstone and Biggins (1986); Menkens et al. (1990); } \\
\text { Powell et al. (1994); Robbins et al. (1986); } \\
\text { Servoss et al. (2000); Engeman and Whisson (2003) }\end{array}$ \\
\hline Dung survey plots & Number of pellet groups in plot & $\begin{array}{l}\text { Ungulates and other } \\
\text { large mammals }\end{array}$ & $\begin{array}{l}\text { Hone (1995); Hone (2002); Hone and Martin (1998); Putman } \\
\text { (1984) }\end{array}$ \\
\hline Road segment scat station & $\begin{array}{l}\text { Number of scats deposited in fixed } \\
\text { time frame in each road segment }\end{array}$ & canids & Andelt and Andelt (1984); Stoddart et al. (2001) \\
\hline
\end{tabular}


counts $Y_{i j}$ as follows (Molenberghs et al., 2007):

$\lambda_{i j}=\theta_{i j} \cdot \exp \left(\mu+s_{i}+d_{j}\right)$

$\left(Y_{i j} \mid \lambda_{i j}\right) \sim \operatorname{Poisson}\left(\lambda_{i j}\right)$.

The term $\theta_{i j}$ is a random effect used to model the overdispersion. It allows departure from the strict mean-variance equality specified by the Poisson distribution. $\theta_{i j}$ is assumed to follow a gamma distribution with $\alpha=\beta$, such that the expected value $E\left(\theta_{i j}\right)=1$ and so does not change the expected value of $Y_{i j}$, and $V\left(\theta_{i j}\right)=1 / \alpha$. This parameterization yields a negative binomial distribution for $Y_{i j}$ conditional on $s_{i}$ and $d_{j}$ which has a known closed form with conditional mean and variance $E\left(Y_{i j} \mid s_{i}, d_{j}\right)=\exp \left(\mu+s_{i}+d_{j}\right)=M_{i j}$ and $V\left(Y_{i j} \mid s_{i}, d_{j}\right)=M_{i j}+\frac{M_{i j}^{2}}{\alpha}$. Smaller values of $\alpha$ give greater overdispersion, and for large values of $\alpha$ this negative binomial converges to a Poisson distribution. The fixed effect term $\mu$ relates to the overall mean count observed on an average station and an average day. Other parameters and random effects are defined analogously to those in the linear model. As described more fully below, this model provides an effective way to simulate counts as they are typically observed in the field, but for which population parameters are known (specified).

\subsection{Assumption of non-zero covariance}

An important feature of both models is that they allow dependence across stations and days. In practice, the observations at different stations are unlikely to be independent geographically, particularly because stations may be near enough together that an animal might encounter multiple stations on the same day. Similarly for example, conditions (and therefore observations) on consecutive days are more likely to be similar than for days further apart. Since the calculation of the variance for $Y_{i j}$ is used for the calculation of the variance of $G I$ (which requires sums), an estimate of the assumed non-zero covariance terms between observations on stations and days was needed.

\subsection{Calculation of variances and covariances}

In order to evaluate the linear model's estimation of index variance, it is helpful to know the expected theoretical variance from the simulation model. Molenberghs et al. (2007) presented the derivation of the mean and variance of overdispersed, correlated count observations from model (2). They provided the theoretical mean and variance for such a random variable with one random effect and the general solution for such a random variable with any number of crossed random effects. We used their general solution for two crossed random effects and derived the theoretical mean and variance of $Y_{i j}$ (each observed count) based on model (2). In order to calculate the variance of GI, it was also necessary to derive the covariances between counts for a station on separate days and between counts from different stations on a single day (Appendix A). This again was an application of the general formula presented by Molenberghs et al. (2007).

\subsection{Parameter estimation}

Engeman (2005) estimated variance components for station $\left(\sigma_{s}^{2}\right)$, day $\left(\sigma_{d}^{2}\right)$, and error $\left(\sigma_{\varepsilon}^{2}\right)$ terms in model (1) using restricted maximum likelihood (REML) in SAS PROC MIXED or PROC VARCOMP (SAS Institute Inc., Cary, NC). Here, the lme function in the nlme package (Pinheiro et al., 2015) in R (R Core Team, 2014) was used, which uses the same estimation method and was free to download and easy to install, in hopes that this approach would offer a simple and reproducible method for future use by a wider audience who may not have access to SAS software (Appendix B). The linear mixed effects model used REML techniques to estimate station, day, and error variance terms, which were then used to estimate $V(G I)$ directly via the equal sample size formula presented previously by Engeman (2005):

$\sigma_{G I}^{2}=V(G I)_{\mathrm{equal}}=\frac{\sigma_{s}^{2}}{S}+\frac{\sigma_{d}^{2}}{D}+\frac{\sigma_{e}^{2}}{S D}$.

\subsection{Simulation setup and validation}

A Monte Carlo simulation study was conducted where conditionally Poisson datasets were simulated from model (2) given in Section 2.2. Recall, the model includes a fixed effect parameter, $\mu$, and random effect parameters for $\theta_{i j} \sim \operatorname{Gamma}(\alpha, \alpha), s_{i} \sim \mathrm{N}\left(0, \sigma_{s}^{2}\right)$, and $d_{j} \sim \mathrm{N}\left(0, \sigma_{d}^{2}\right)$. Values for $\mu, \alpha, \sigma_{s}$, and $\sigma_{d}$ were specified in the simulation and 1000 data sets were produced for each parameter combination. For results to be of practical application, it was essential that the model parameterizations produce simulated data resembling typical field observations, which we based on a great many field studies from around the world, such as those referenced in Table 1, the 40 indexing studies referenced in Table 1 of Allen et al. (2013b), the multi-year indexing data and results for 14 species from nine sites across a wide swath of Australia described in Allen et al. (2013a, 2014).

All parameters in the simulations were pre-specified and selected, as described above, after confirming that the resulting generated counts were reasonable representations of datasets that might be collected in field studies in many parts of the world. Because Monte Carlo simulation studies involve the simulation of data by randomly sampling from a known, pre-specified distribution (or model), datasets were provided where the "true" or correct answer is known (which is not the case with observed data collected from the field). Multiple statistical analyses can then be applied to the simulated data and their resulting parameter estimates can then be compared to the true parameters used to generate the data, thereby allowing a clear evaluation estimation performance. Statistical properties such as low bias (estimated parameters are on average similar to true/input values) and good coverage (true/ input parameters are included in the estimated confidence intervals) indicate the estimation and inference methods are valid.

We first conducted simulations using the 16 parameter combinations of: $\mu=-0.1$ and $0 ; \alpha=0.5$ and $1.5 ; \sigma_{s}=0.10$ and $0.35 ; \sigma_{d}=$ 0.05 and 0.25 . All simulated data sets were given 40 stations of observation. Simulations using these 16 combinations of parameter values were initially conducted using 4 observation days and then repeated to consider 2 and 8 observation days. Based on what we observed concerning the influence of $\sigma_{d}$ in those results, we further explored the impact on estimation quality when increasing the input (true) values for $\sigma_{d}$. Thus, simulations considering another 16 parameter combinations were repeated using the same parameterizations as initially for $\mu, \alpha$, and $\sigma_{s}$, but now with $\sigma_{d}$ values of 0.35 and 0.55 .

\subsection{Evaluation of estimates}

For each data set, a $95 \% \mathrm{CI}$ for the index as $\mathrm{GI} \pm 1.96 \mathrm{SE}_{G I}$ was constructed, with the standard error calculated as the square root of the variance of GI in Eq. (3) using the estimated station, day and error variances. The linear mixed model estimation was assessed using coverage rates of the theoretical expected value of $G I$ by the resulting confidence intervals, based on the input simulation parameters and the derived formula from model (2), $E(G I)=\exp \left(\mu+\frac{\sigma_{s}^{2}}{2}+\frac{\sigma_{d}^{2}}{2}\right)$.

\section{Results}

Simulation results using the initially specified parameter values and 4 observation days demonstrated acceptable estimation for the linear model in general, with coverage rates ranging from 0.88 to 0.96 (Table 2). One clear trend was that coverage rates were very close to 0.95 with pre-specified input (true) $\sigma_{d}$ values of 0.05 , with a mean coverage rate of 0.948 . Specifying $\sigma_{d}$ values of 0.25 resulted in coverage rates consistently lower, near 0.90 , with a mean coverage rate of 
Table 2

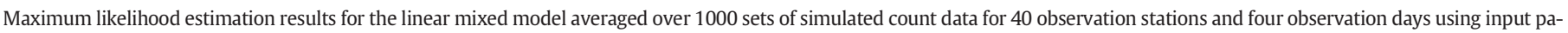

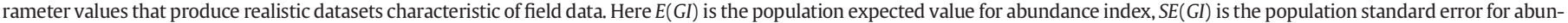

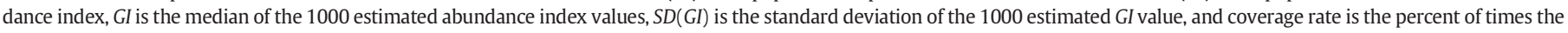
$95 \%$ confidence interval covered the true $E(G I)$.

\begin{tabular}{|c|c|c|c|c|c|c|c|c|c|c|}
\hline & & & & \multicolumn{2}{|c|}{ Data set descriptive statistics } & \multicolumn{2}{|c|}{ Theoretical values } & \multicolumn{2}{|c|}{ Median estimate } & \multirow{3}{*}{ Coverage rate for $95 \% \mathrm{CI}$} \\
\hline \multicolumn{4}{|c|}{$\begin{array}{l}\text { Input values } \\
\text { ( } 1000 \text { datasets simulated } \\
\text { for each combination) }\end{array}$} & \multirow[t]{2}{*}{ Max count (median) } & \multirow[t]{2}{*}{ Proportion $0 \mathrm{~s}$ (median) } & \multirow[t]{2}{*}{$E(G I)$} & \multirow[t]{2}{*}{$S E(G I)$} & \multirow[t]{2}{*}{$G I$} & \multirow[t]{2}{*}{$S D(G I)$} & \\
\hline$\alpha$ & $\mu$ & $\sigma_{s}$ & $\sigma_{d}$ & & & & & & & \\
\hline \multirow[t]{8}{*}{1.5} & \multirow[t]{4}{*}{-0.10} & \multirow[t]{2}{*}{0.10} & 0.05 & 6 & 0.494 & 0.911 & 0.100 & 0.900 & 0.106 & 0.958 \\
\hline & & & 0.25 & 6 & 0.494 & 0.938 & 0.156 & 0.925 & 0.136 & 0.886 \\
\hline & & \multirow[t]{2}{*}{0.35} & 0.05 & 7 & 0.494 & 0.963 & 0.118 & 0.956 & 0.121 & 0.952 \\
\hline & & & 0.25 & 7 & 0.494 & 0.993 & 0.174 & 0.975 & 0.157 & 0.893 \\
\hline & \multirow[t]{4}{*}{0} & \multirow[t]{2}{*}{0.10} & 0.05 & 7 & 0.469 & 1.006 & 0.107 & 1.000 & 0.114 & 0.960 \\
\hline & & & 0.25 & 7 & 0.469 & 1.037 & 0.170 & 1.019 & 0.151 & 0.890 \\
\hline & & \multirow[t]{2}{*}{0.35} & 0.05 & 8 & 0.469 & 1.064 & 0.128 & 1.063 & 0.132 & 0.942 \\
\hline & & & 0.25 & 8 & 0.466 & 1.097 & 0.190 & 1.075 & 0.169 & 0.883 \\
\hline \multirow[t]{8}{*}{0.5} & \multirow[t]{4}{*}{-0.10} & \multirow[t]{2}{*}{0.10} & 0.05 & 9 & 0.600 & 0.911 & 0.130 & 0.894 & 0.138 & 0.941 \\
\hline & & & 0.25 & 10 & 0.600 & 0.938 & 0.179 & 0.919 & 0.157 & 0.908 \\
\hline & & \multirow[t]{2}{*}{0.35} & 0.05 & 11 & 0.600 & 0.963 & 0.151 & 0.947 & 0.155 & 0.942 \\
\hline & & & 0.25 & 11 & 0.600 & 0.993 & 0.200 & 0.963 & 0.176 & 0.916 \\
\hline & \multirow[t]{4}{*}{0} & \multirow[t]{2}{*}{0.10} & 0.05 & 10 & 0.575 & 1.006 & 0.141 & 1.000 & 0.152 & 0.950 \\
\hline & & & 0.25 & 10 & 0.581 & 1.037 & 0.196 & 1.006 & 0.173 & 0.904 \\
\hline & & \multirow[t]{2}{*}{0.35} & 0.05 & 11 & 0.575 & 1.064 & 0.165 & 1.050 & 0.169 & 0.939 \\
\hline & & & 0.25 & 12 & 0.581 & 1.097 & 0.220 & 1.075 & 0.195 & 0.913 \\
\hline
\end{tabular}

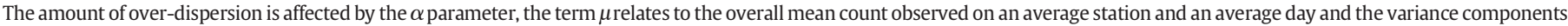
for station and day are denoted by $\sigma_{s}^{2}$ and $\sigma_{d}^{2}$, respectively.

0.899 , and larger values of $\sigma_{d}$ resulted in continued reduction in coverage rates. With only two days of observation, coverage ranged from 0.85 to 0.95 , a slight loss in coverage compared to four days (Table 3). Eight days of observation increased overall coverage slightly, ranging from 0.90 to 0.97 (Table 4). As the number of observation days increased, the magnitude of $\sigma_{d}$ had less of an effect on coverage rates (Tables 2, 3, 4).

Simulations using larger input values for $\sigma_{d}$ of 0.35 and 0.55 (with other original input values unchanged) resulted in mean coverage rates of 0.868 and 0.819 , respectively (Table 5 ). While coverage rates near 0.80 would be a cause for concern for the practitioner, the data sets simulated from such large input values for this parameter did not correspond to those typically seen in the field, as the counts generated from these values were unusually higher than those typically observed in practice (median highest count per dataset ranged from 7 to 14 , as compared to the data seen in references listed in Table 1, the references in Table 1 of Allen et al. (2013b), the multi-year indexing data and results for 14 species in Allen et al. (2013a, 2014).

The magnitude of $\sigma_{d}$ was found to have a greater impact on coverage rates than the magnitude of $\sigma_{s}$. Coverage rates decreased substantially for larger $\sigma_{d}$ but only slightly for larger $\sigma_{s}$ (Tables 2-5). In fact, coverage rates were quite consistent for constant $\sigma_{d}$, even as $\sigma_{s}$ is varied.

Table 3

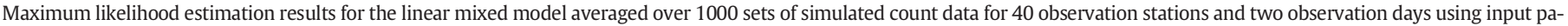

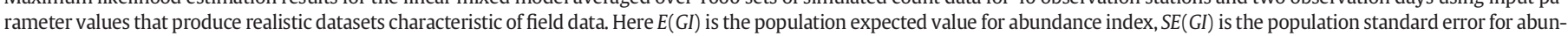

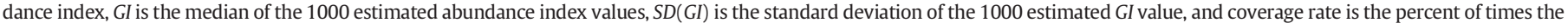
$95 \%$ confidence interval covered the true $E(G I)$.

\begin{tabular}{|c|c|c|c|c|c|c|c|c|c|c|}
\hline & & & & \multicolumn{2}{|c|}{ Data set descriptive statistics } & \multicolumn{2}{|c|}{ Theoretical values } & \multicolumn{2}{|c|}{ Median estimate } & \multirow{3}{*}{ Coverage rate for $95 \% \mathrm{CI}$} \\
\hline \multicolumn{4}{|c|}{$\begin{array}{l}\text { Input values } \\
\text { (1000 datasets simulated } \\
\text { for each combination) }\end{array}$} & Max count (median) & Proportion $0 \mathrm{~s}$ (median) & $E(G I)$ & $S E(G I)$ & GI & $S D(G I)$ & \\
\hline$\alpha$ & $\mu$ & $\sigma_{s}$ & $\sigma_{d}$ & & & & & & & \\
\hline \multirow[t]{8}{*}{1.5} & \multirow{4}{*}{-0.10} & \multirow[t]{2}{*}{0.10} & 0.05 & 5 & 0.488 & 0.911 & 0.140 & 0.900 & 0.148 & 0.946 \\
\hline & & & 0.25 & 6 & 0.500 & 0.938 & 0.220 & 0.900 & 0.167 & 0.853 \\
\hline & & \multirow[t]{2}{*}{0.35} & 0.05 & 6 & 0.494 & 0.963 & 0.158 & 0.950 & 0.163 & 0.937 \\
\hline & & & 0.25 & 6 & 0.500 & 0.993 & 0.240 & 0.950 & 0.188 & 0.857 \\
\hline & \multirow[t]{4}{*}{0} & \multirow[t]{2}{*}{0.10} & 0.05 & 6 & 0.463 & 1.006 & 0.150 & 0.988 & 0.157 & 0.948 \\
\hline & & & 0.25 & 6 & 0.463 & 1.037 & 0.240 & 1.000 & 0.182 & 0.850 \\
\hline & & \multirow[t]{2}{*}{0.35} & 0.05 & 6 & 0.469 & 1.064 & 0.171 & 1.038 & 0.174 & 0.939 \\
\hline & & & 0.25 & 7 & 0.463 & 1.097 & 0.262 & 1.063 & 0.200 & 0.858 \\
\hline \multirow[t]{8}{*}{0.5} & \multirow[t]{4}{*}{-0.10} & \multirow[t]{2}{*}{0.10} & 0.05 & 8 & 0.600 & 0.911 & 0.183 & 0.894 & 0.193 & 0.925 \\
\hline & & & 0.25 & 8 & 0.600 & 0.938 & 0.253 & 0.913 & 0.217 & 0.891 \\
\hline & & \multirow[t]{2}{*}{0.35} & 0.05 & 9 & 0.600 & 0.963 & 0.206 & 0.938 & 0.216 & 0.935 \\
\hline & & & 0.25 & 9 & 0.600 & 0.993 & 0.278 & 0.963 & 0.238 & 0.883 \\
\hline & \multirow[t]{4}{*}{0} & \multirow[t]{2}{*}{0.10} & 0.05 & 8 & 0.575 & 1.006 & 0.199 & 0.988 & 0.216 & 0.943 \\
\hline & & & 0.25 & 9 & 0.575 & 1.037 & 0.277 & 1.013 & 0.231 & 0.884 \\
\hline & & \multirow[t]{2}{*}{0.35} & 0.05 & 9 & 0.575 & 1.064 & 0.225 & 1.038 & 0.234 & 0.940 \\
\hline & & & 0.25 & 10 & 0.575 & 1.097 & 0.305 & 1.063 & 0.255 & 0.892 \\
\hline
\end{tabular}

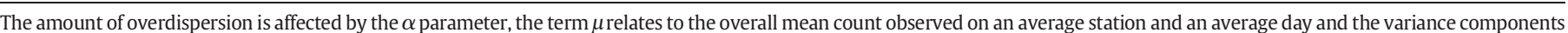
for station and day are denoted by $\sigma_{s}^{2}$ and $\sigma_{d}^{2}$, respectively. 
Table 4

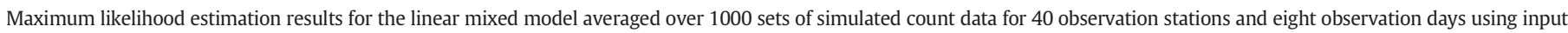

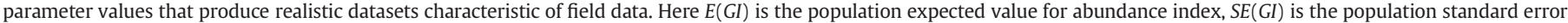

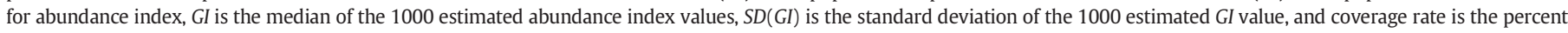
of times the $95 \%$ confidence interval covered the true $E(G I)$.

\begin{tabular}{|c|c|c|c|c|c|c|c|c|c|c|}
\hline & & & & \multicolumn{2}{|c|}{ Data set descriptive statistics } & \multicolumn{2}{|c|}{ Theoretical values } & \multicolumn{2}{|c|}{ Median estimate } & \multirow{3}{*}{ Coverage rate for $95 \% \mathrm{CI}$} \\
\hline \multicolumn{4}{|c|}{$\begin{array}{l}\text { Input values } \\
\text { ( } 1000 \text { datasets simulated } \\
\text { for each combination) }\end{array}$} & Max count (median) & Proportion $0 \mathrm{~s}$ (median) & $E(G I)$ & $S E(G I)$ & $G I$ & $S D(G I)$ & \\
\hline$\alpha$ & $\mu$ & $\sigma_{s}$ & $\sigma_{d}$ & & & & & & & \\
\hline \multirow[t]{8}{*}{1.5} & -0.10 & 0.10 & 0.05 & 7 & 0.494 & 0.911 & 0.071 & 0.903 & 0.074 & 0.965 \\
\hline & & & 0.25 & 7 & 0.491 & 0.938 & 0.111 & 0.928 & 0.103 & 0.914 \\
\hline & & 0.35 & 0.05 & 8 & 0.494 & 0.963 & 0.092 & 0.956 & 0.092 & 0.936 \\
\hline & & & 0.25 & 9 & 0.491 & 0.993 & 0.129 & 0.978 & 0.122 & 0.910 \\
\hline & 0 & 0.10 & 0.05 & 7 & 0.466 & 1.006 & 0.077 & 1.000 & 0.079 & 0.955 \\
\hline & & & 0.25 & 8 & 0.463 & 1.037 & 0.121 & 1.025 & 0.113 & 0.913 \\
\hline & & 0.35 & 0.05 & 8 & 0.466 & 1.064 & 0.100 & 1.059 & 0.100 & 0.945 \\
\hline & & & 0.25 & 9 & 0.469 & 1.097 & 0.142 & 1.081 & 0.132 & 0.903 \\
\hline \multirow[t]{8}{*}{0.5} & -0.10 & 0.10 & 0.05 & 11 & 0.597 & 0.911 & 0.093 & 0.909 & 0.098 & 0.957 \\
\hline & & & 0.25 & 11 & 0.597 & 0.938 & 0.127 & 0.928 & 0.118 & 0.899 \\
\hline & & 0.35 & 0.05 & 13 & 0.597 & 0.963 & 0.114 & 0.950 & 0.115 & 0.939 \\
\hline & & & 0.25 & 13 & 0.597 & 0.993 & 0.147 & 0.981 & 0.134 & 0.923 \\
\hline & 0 & 0.10 & 0.05 & 12 & 0.578 & 1.006 & 0.101 & 1.002 & 0.107 & 0.950 \\
\hline & & & 0.25 & 12.5 & 0.578 & 1.037 & 0.139 & 1.025 & 0.132 & 0.933 \\
\hline & & 0.35 & 0.05 & 14 & 0.575 & 1.064 & 0.124 & 1.063 & 0.127 & 0.940 \\
\hline & & & 0.25 & 14 & 0.581 & 1.097 & 0.162 & 1.072 & 0.149 & 0.910 \\
\hline
\end{tabular}

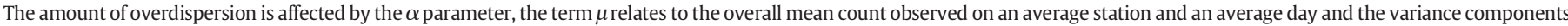
for station and day are denoted by $\sigma_{s}^{2}$ and $\sigma_{d}^{2}$, respectively.

\section{Discussion}

Accurate knowledge of absolute animal abundance is near impossible to acquire in the field (Caughley, 1977; Pollock, 1995; Sutherland, 1996). The primary driving force for applying abundance indexing procedures is that they are practical or feasible methods for tracking animal populations. When the principles outlined in Engeman (2005) are strictly applied, researchers can acquire reliable estimates of relative abundance (indices of abundance). A relative abundance index is maximally informative when taken in context with comparative values to assess trends, changes or differences (Engeman, 2005; Krebs, 2008). Thus, valid statistical comparison methods among index values are essential. Statistical theory has been developed for a broad class of indexing approaches (Engeman, 2005) and methods for validating indexing procedures have been delineated (Allen and Engeman, 2015). The missing piece in this picture has concerned the validity of applying Gaussian-based statistical inference when index values were obtained from count data (i.e., Poisson-distributed data). The present study has addressed that need.

The mixed effects linear model performed well in estimating indices and their variances and confidence intervals when simulated counts are in the range typically obtained in field studies. Two conditions that improved estimation quality were identified. First, estimation improved with additional observation days. Second, the model performed very well in terms of confidence interval coverage rates even with few days when the day-to-day variability $\left(\sigma_{d}\right)$ was small. Effective estimation was observed for a large range of values of station-to-station variability $\left(\sigma_{s}\right)$. From experience, fortunately, day-to-day variability is

\section{Table 5}

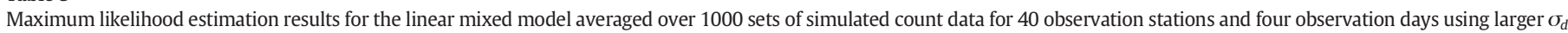

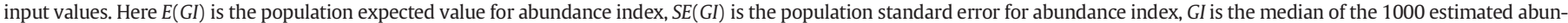
dance index values, $S D(G I)$ is the standard deviation of the 1000 estimated GI value, and coverage rate is the percent of times the $95 \%$ confidence interval covered the true $E(G I)$.

\begin{tabular}{|c|c|c|c|c|c|c|c|c|c|c|}
\hline & & & & \multicolumn{2}{|c|}{ Data set descriptive statistics } & \multicolumn{2}{|c|}{ Theoretical values } & \multicolumn{2}{|c|}{ Median estimate } & \multirow{3}{*}{ Coverage rate for $95 \% \mathrm{Cl}$} \\
\hline \multicolumn{4}{|c|}{$\begin{array}{l}\text { Input values } \\
\text { ( } 1000 \text { datasets simulated } \\
\text { for each combination) }\end{array}$} & Max count (median) & Proportion $0 \mathrm{~s}$ (median) & $E(G I)$ & $S E(G I)$ & $G I$ & $S D(G I)$ & \\
\hline$\alpha$ & $\mu$ & $\sigma_{s}$ & $\sigma_{d}$ & & & & & & & \\
\hline \multirow[t]{8}{*}{1.5} & -0.10 & 0.10 & 0.35 & 7 & 0.494 & 0.967 & 0.203 & 0.956 & 0.169 & 0.856 \\
\hline & & & 0.55 & 8 & 0.491 & 1.058 & 0.335 & 1.013 & 0.242 & 0.807 \\
\hline & & 0.35 & 0.35 & 8 & 0.488 & 1.023 & 0.223 & 1.000 & 0.186 & 0.866 \\
\hline & & & 0.55 & 9 & 0.494 & 1.119 & 0.361 & 1.072 & 0.266 & 0.819 \\
\hline & 0 & 0.10 & 0.35 & 7 & 0.463 & 1.068 & 0.223 & 1.050 & 0.186 & 0.843 \\
\hline & & & 0.55 & 8 & 0.469 & 1.169 & 0.369 & 1.125 & 0.278 & 0.814 \\
\hline & & 0.35 & 0.35 & 9 & 0.463 & 1.130 & 0.245 & 1.119 & 0.205 & 0.882 \\
\hline & & & 0.55 & 10 & 0.469 & 1.237 & 0.397 & 1.175 & 0.286 & 0.822 \\
\hline \multirow[t]{8}{*}{0.5} & -0.10 & 0.10 & 0.35 & 10 & 0.600 & 0.967 & 0.224 & 0.938 & 0.180 & 0.877 \\
\hline & & & 0.55 & 12 & 0.594 & 1.058 & 0.353 & 1.013 & 0.263 & 0.841 \\
\hline & & 0.35 & 0.35 & 12 & 0.600 & 1.023 & 0.246 & 1.000 & 0.201 & 0.872 \\
\hline & & & 0.55 & 13 & 0.594 & 1.119 & 0.382 & 1.066 & 0.279 & 0.823 \\
\hline & 0 & 0.10 & 0.35 & 11 & 0.581 & 1.068 & 0.246 & 1.031 & 0.196 & 0.870 \\
\hline & & & 0.55 & 12 & 0.581 & 1.169 & 0.390 & 1.100 & 0.274 & 0.827 \\
\hline & & 0.35 & 0.35 & 13 & 0.581 & 1.130 & 0.271 & 1.103 & 0.224 & 0.882 \\
\hline & & & 0.55 & 14 & 0.581 & 1.237 & 0.421 & 1.156 & 0.296 & 0.801 \\
\hline
\end{tabular}

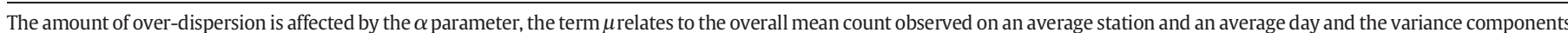
for station and day are denoted by $\sigma_{s}^{2}$ and $\sigma_{d}^{2}$, respectively. 
most often small in comparison to station-to-station variability (e.g., Engeman et al., 2000, 2003; Whisson et al., 2005), although there are instances where the reverse is true (Engeman and Whisson, 2003).

Considering that our results show that small day-to-day variability and/or increasing the number of observation days improves estimation quality, while field experience indicates that day-to-day variability tends to be less impactful than station-to-station variability, leads us to also consider how to design field studies involving count data. Rather than be reliant on the likelihood that day-to-day variability would not be impactful, the conscientious researcher would evaluate design approaches to promote quality estimation.

The most obvious consideration for assuring estimation quality would seem to be to maximize the number of observation days in the field. However, this is not as straight-forward as it seems and there are constraints to this approach. In reality, logistics and resources often are the most important influences on sampling designs for wildlife surveys (Engeman, 2005). Increased observation days can come at a cost in time or expense in the field that is not practical or obtainable. An exception to this is the use of camera traps where modern high capacity memory cards and long-lasting batteries allow cameras to remain in the field for extended periods of time. Even this seemingly idyllic situation has drawbacks. First, when indexing animal populations, studies can be invalidated by assuming no changes occur in an extended time frame (Engeman, 2005). Thus, even if cameras remain installed and working the whole time, it might well be reasonable to break that extended period into smaller segments for population indexing snapshots at different times. Furthermore, data collection over an extended time period increases the chance that data would be collected during changing weather patterns or during other natural or manmade dynamic events that affect animal behavior. More than likely, this would increase day-today variability in the data, which in turn decreases estimation quality and could negate the beneficial impact of maximizing observation days.

The other design consideration from our results whereby improved estimation quality could be facilitated would be to implement the data collection such that day-to-day variability is minimized. Environmental and external factors can affect animal behavior and not all contingencies can be accounted for in the design of a field study. However, it is possible to read a weather forecast and plan accordingly for short-term observation occasions during stable weather. Moreover, not only does inclement weather tend to increase day-to-day variability, it can also serve to destroy data. For example, precipitation and wind can erase track plots, waterproof trail cameras often turn out to not be truly waterproof, or water, snow, or mud gets splashed over the lens, resulting in unintelligible photographs. It is also possible to identify and avoid time periods when there are significant human disturbances like hunting seasons, cattle roundups, prescribed burns, infrastructure work on power or gas lines, and times of increased recreation (i.e., holidays). If data must be collected during a period when animal behavior might be changing due to an outside influence, then every effort should be made to maximize the number of observation days. Clearly, a combination of using study resources to optimize the number of observation days while also avoiding as best as possible, within the confines of study logistics and resources, circumstances that would increase day-to-day variability would offer the best opportunity for the highest possible estimation quality. By so doing, the general index and the linear mixed model method using maximum likelihood estimation is a reliable means of comparing population index values even though observations may consist of small counts.

Quality estimation leads to quality inferences which in turn support policy decisions and decisions for management actions. For example, at a high-density sea turtle nesting beach in Florida where nest losses to predation sometimes reached as high as $95 \%$, predator removal was identified as the most important management program at the beach (e.g. Engeman et al., 2003; U.S. Fish and Wildlife Service, 2000). However, only limited manpower and resources have been available to carry out the necessary control work, while too much predator control activity on the beach could result in disturbances to the sea turtle nesting activity. Engeman et al. (2003) developed and applied a passive track plot observation station to monitor predators, with the resulting count data analyzed according to the GI methodology. The resulting information was particularly valuable because it allowed managers to choose a corrective (real time) control approach over a preventative approach, which would have resulted in wasted control resources and a failure to protect the turtle nests (Engeman et al., 2003). Moreover, the data collection and analytical methodology allowed the impact of restricted resources for predator removal efforts to be optimized by: 1) optimizing the timing and strategy for application of predator removal, 2) minimizing labor by identifying areas where predator removal would have maximal effect, 3) examining beach invasion patterns of predators, 4) assessing predator removal efficacy, 5) providing anticipatory information for future turtle nesting seasons, and 6) serving as a detection method for invasion by additional species known to depredate turtle nests (Engeman et al., 2003). The resulting success had been unimaginable (Engeman et al., 2003), and after many years of this approach the additional hatchling sea turtles saved from nest predation and entering the ocean from this beach numbers in the millions.

As another example of the great utility of inference from indices based on counts, in Australia there has been national debate on whether dingo (Canis lupus dingo) control to protect livestock has deleterious effects on native fauna by releasing populations of invasive red foxes (Vulpes vulpes), and feral cats (Felis catus), which in turn would hypothetically prey on and threaten small sympatric prey species (e.g., Allen et al., 2011). Lethal dingo control practices have received increased scrutiny recently for their perceived indirect benefits to fox and cat populations, culminating in calls to prohibit lethal dingo control with the expectation that dingoes will then reduce the abundance of foxes and cats and therefore their impacts on threatened prey (Allen et al., 2011, 2013a, 2014). To address this issue in a definitive fashion, Allen et al. (2013a, 2014) used a series of predator manipulation experiments (those with the highest level of inference) logistically achievable in open rangeland areas to determine (1) whether or not sympatric mesopredator (foxes and cats) abundances were higher, or became higher in areas subjected to top-predator control, (2) whether or not sympatric mesopredator activity levels increased immediately after top-predator control, and (3) how sympatric mesopredator abundance trends correlated with top-predator abundance trends over time. These experiments were conducted over a large swath of Australian rangelands that cover around a third of the continent (Allen et al., 2013a, 2014). The inferences concerning relationships among 14 species of predators and prey were reliant on simultaneously monitoring the species found in each of the nine study areas. Population monitoring was conducted by indexing each species abundance using passive tracking plots with observations typically consisting of small counts of track intrusions that included an over-dispersion of zeroes (Allen et al., 2013a, 2014), with analyses conducted using general index and the linear mixed model method using maximum likelihood estimation coupled with Gaussian-based inference as was evaluated in the current paper. Their results provided strong, experimental evidence that contemporary dingo control practices did not produce immediate or sustained positive overall responses from mesopredators in the beefcattle rangelands of Australia, nor did they show that cessation of dingo control reduced mesopredator abundances. They were led to assert that proposals to cease dingo control are presently unjustified on grounds that contemporary dingo control somehow releases mesopredators and threatens prey fauna through trophic cascade effects. Contemporary top-predator control might continue to be practiced for protection of livestock and native fauna in ways compatible with biodiversity conservation (Allen et al., 2013a, 2014).

There are a vast number of examples from around the world where valuable information is obtained through indexing animal abundance with methods involving small counts. Most, probably, are as straightforward as assessing whether a particular management action affected the abundance of a species in an area, although there are also many 
instances, such as the examples above, where much more complicated relationships and inferences are investigated. Our results provide a foundational basis for applying the general indexing paradigm to count data, strengthen the generality of the approach, provide valuable information for study design, and should reassure practitioners about the validity of their analytical inferences when using these methods with count data.

\section{Appendix A. Derivation of $V(G I)$ from model (2), overdispersed Poisson model with crossed random effects}

\section{A.1. Variance of $Y_{i j}$}

The variance of $Y_{i j}$ can be calculated from Molenberghs et al. (2007) Eq. (37) applied to model (2). There, $E\left(\theta_{i j}\right)=1, E\left(\theta_{i j}^{2}\right)=V\left(\theta_{i j}\right)+E\left(\theta_{i j}\right)^{2}=$ $\frac{1}{\alpha}+1$, and with $\kappa_{i j}=\exp \left(\mu+s_{i}+d_{j}\right)$, Molenberghs et al. (2007) Eqs. (41) and (42) give $E\left(\kappa_{i j}\right)=\exp \left(\mu+\frac{\sigma_{s}^{2}}{2}+\frac{\sigma_{d}^{2}}{2}\right)$ and $E\left(\kappa_{i j}^{2}\right)=$ $V\left(\kappa_{i j}\right)+E\left(\kappa_{i j}\right)^{2}=\exp \left(2 \mu+2 \sigma_{s}^{2}+2 \sigma_{d}^{2}\right)$. Eq. (37) then gives $V\left(Y_{i j}\right)=\exp (\mu$ $\left.+\frac{\sigma_{s}^{2}}{2}+\frac{\sigma_{d}^{2}}{2}\right)+\left(\frac{1}{\alpha}+1\right) \exp \left(2 \mu+2 \sigma_{s}^{2}+2 \sigma_{d}^{2}\right)-\exp \left(2 \mu+\sigma_{s}^{2}+\sigma_{d}^{2}\right)$. Using $E\left(Y_{i j}\right)=\exp \left(\mu+\frac{\sigma_{s}^{2}}{2}+\frac{\sigma_{d}^{2}}{2}\right) \equiv m$ this can be written as $V\left(Y_{i j}\right)=m+m^{2}\left[\left(\frac{1}{\alpha}+\right.\right.$ $1 \operatorname{expos} 2+\sigma \mathrm{d} 2-1$.

\section{A.2. Variance of $G I$}

The general index GI is calculated as (Engeman, 2005) $G I=\frac{1}{D}$ $\sum_{j=1}^{D} \frac{1}{S_{j}} \sum_{i=1}^{S_{j}} Y_{i j} \quad$ with variance $\quad V(G I)=\left(\frac{1}{D} \sum_{j=1}^{D} \frac{1}{S_{j}} \sum_{i=1}^{S_{j}} Y_{i j}\right)=\frac{1}{D^{2}}$ $\sum_{j=1}^{D} \sum_{k=1}^{D} \frac{1}{S_{j}} \frac{1}{S_{k}} \sum_{i=1}^{S_{j}} \sum_{n=1}^{S_{k}} \operatorname{Cov}\left(Y_{i j}, Y_{n k}\right)$. When $S_{j}=S$ for all $j$, as in our simulations, the variance simplifies to $V(G I)=\left(\frac{1}{D S}\right)^{2}\left[D S C o v\left(Y_{i j}, Y_{i j}\right)\right.$ +DSS-1CovYij, Ynj + DSD-1CovYij, Yik + DS $(D-1)(S-1)$ CovYik, Ynk . The covariance terms are

$$
\begin{aligned}
& \operatorname{Cov}\left(Y_{i j}, Y_{i j}\right)=m+m^{2}\left[\left(\frac{1}{\alpha}+1\right) \exp \left(\sigma_{s}^{2}+\sigma_{d}^{2}\right)-1\right] \text { for } i=n \text { and } j=k \\
& \operatorname{Cov}\left(Y_{i j}, Y_{n j}\right)=m^{2}\left(e^{\sigma_{d}^{2}}-1\right) \quad \text { for } i \neq n \text { and } j=k \\
& \operatorname{Cov}\left(Y_{i j}, Y_{i k}\right)=m^{2}\left(e^{\sigma_{s}^{2}}-1\right) \quad \text { for } i=n \text { and } j \neq k \\
& \operatorname{Cov}\left(Y_{i j}, Y_{n k}\right)=0 \quad \text { for } i \neq n \text { and } j \neq k \text {. }
\end{aligned}
$$

\section{Appendix B. $R$ code for estimating model (1)}

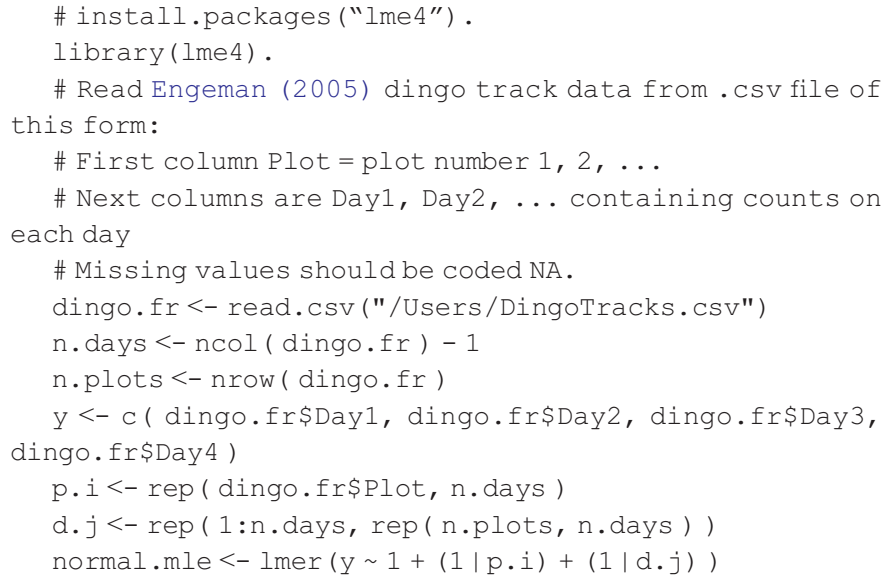

\section{References}

Allen, L.R., Engeman, R.M., 2015. Evaluating and validating abundance monitoring methods in absence of populations of known size. Environ. Sci. Pollut. Res. 22 2907-2915.
Allen, L.R., Engeman, R.M., Krupa, H., 1996. Evaluation of three relative abundance indices for assessing dingo populations. Wildl. Res. 23, 197-206.

Allen, B.L., Engeman, R.M., Allen, L.R., 2011. Wild dogma I: an examination of recent "evidence" for dingo regulation of invasive mesopredator release in Australia. Curr. Zool. 57, 568-583.

Allen, B.L., Fleming, P.J.S., Hayward, M., Allen, L.R., Engeman, R.M., Ballard, G., Leung, L.K.P., 2012. Top predators as biodiversity regulators: contemporary issues affecting knowledge and management of dingoes in Australia. In: Lameed, G.A. (Ed.), Biodiversity Enrichment in a Diverse World. InTech Publishing, Rijeka, Croatia, pp. 85-132.

Allen, B.L., Allen, L.R., Engeman, R.M., Leung, L.K.-P., 2013a. Intraguild relationships between sympatric predators exposed to lethal control: predator manipulation experiments. Front. Zool. 10, 39.

Allen, B.L., Fleming, P.J.S., Hayward, M., Allen, L.R., Engeman, R.M., Ballard, G., Leung, L.K.P., 2013b. As clear as mud: a critical review of evidence for the ecological roles of Australian dingoes. Biol. Conserv. 159, 158-174.

Allen, B.L., Allen, L.R., Engeman, R.M., Leung, L.K.-P., 2014. Sympatric prey responses to lethal top-predator control: predator manipulation experiments. Front. Zool. 11, 56.

Allison, N.L., Destefano, S., 2006. Equipment and techniques for nocturnal wildlife studies Wildl. Soc. Bull. 34, 1036-1044.

Andelt, W.F., Andelt, S.H., 1984. Diet bias in scat deposition rate surveys of coyote density Wildl. Soc. Bull. 12, 74-77.

Anderson, D.R., 2001. The need to get the basics right in wildlife field studies. Wildl. Soc Bull. 29, 1294-1297.

Anthony, R.M., Barnes Jr., V.G., 1983. Plot occupancy for indicating pocket gopher abundance and conifer damage. In: Kaukeinen, D.E. (Ed.), Vertebrate Pest Control and Management Materials: Fourth Symposium, ASTM STP 817. American Society for Testing and Materials, Philadelphia, pp. 247-255.

Beard, L.A., 1999. Training observers. Aust. Zool. 31, 287-291.

Bengsen, A.J., Leung, L.K.-P., Lapidge, S.J., Gordon, I.J., 2011. Using a general index approach to analyze camera-trap abundance indices. J. Wildl. Manag. 75, 1222-1227.

Caughley, G., 1977. Analysis of Vertebrate Populations. Wiley, London.

Choquenot, D., Kay, B., Lukins, B.S., 1990. An evaluation of warfarin for the control of feral pigs. J. Wildl. Manag. 54, 353-359.

R Core Team, 2014. R: A language and environment for statistical computing. R Foundation for Statistical Computing, Vienna, Austria (http://www.R-project.org/).

De Bondi, N., White, J.G., Stevens, M., Cooke, R., 2010. A comparison of the effectiveness of camera trapping and live trapping for sampling terrestrial small-mammal communities. Wildl. Res. 37, 456-465.

Engeman, R.M., 2003. More on the need to get the basics right: population indices. Wildl. Soc. Bull. 31, 286-287.

Engeman, R.M., 2005. Indexing principles and a widely applicable paradigm for indexing animal populations. Wildl. Res. 32, 203-210.

Engeman, R.M., Allen, L.R., 2000. Overview of a passive tracking index for monitoring wild canids and associated species. Integr. Pest Manag. Rev. 5, 197-203.

Engeman, R.M., Evangelista, P., 2006. Investigating the feasibility of a passive tracking index for monitoring wildlife in the lower Omo Valley, Ethiopia. Afr. J. Ecol. 45, 184-188.

Engeman, R.M., Whisson, D.A., 2003. A visual method for indexing muskrat populations. Int. Biodeterior. Biodegrad. 52, 101-106.

Engeman, R.M., Campbell, D.L., Evans, J., 1993. A comparison of 2 activity measures for northern pocket gophers. Wildl. Soc. Bull. 21, 70-73.

Engeman, R.M., Pipas, M.J., Gruver, K.S., Allen, L.R., 2000. Monitoring coyote populations with a passive activity index. Wildl. Res. 27, 553-557.

Engeman, R.M., Martin, R.E., Constantin, B., Noel, R., Woolard, J., 2003. Monitoring predators to optimize turtle nest protection through control. Biol. Conserv. 113, 171-178.

Engeman, R.M., Massei, G., Sage, M., Gentle, M.N., 2013. Monitoring wild pig populations: a review of methods. Environ. Sci. Pollut. Res. 20, 8077-8091.

Fagerstone, K.A., Biggins, D.E., 1986. Comparison of capture-recapture and visual count indices of prairie dog densities in black-footed ferret habitat. Great Basin Nat. Mem. 8, 94-98.

Fitzmaurice, G., Davidian, M., Verbeke, G., Molenberghs, G., 2008. Longitudinal Data Analysis. Chapman \& Hall/CRC.

Focardi, S., De Marinis, A.M., Rizzotto, M., Pucci, A., 2001. Comparative evaluation of thermal infrared imaging and spotlighting to survey wildlife. Wildl. Soc. Bull. 29 133-139.

Hone, J., 1995. Spatial and temporal aspects of vertebrate pest damage with emphasis on feral hogs. J. Appl. Ecol. 32, 311-319.

Hone, J., 2002. Feral pigs in Namadgi National Park, Australia: dynamics, impacts and management. Biol. Conserv. 105, 231-242.

Hone, J., Martin, W., 1998. A study of dung decay and plot size for surveying feral pigs using dung counts. Wildl. Res. 25, 255-260.

Krebs, C.J., 2008. Ecology: The Experimental Analysis of Distribution And Abundance. Benjamin-Cummings Publishing, San Francisco.

Mahon, P.S., Banks, P.B., Dickman, C.R., 1998. Population indices for wild carnivores: a critical study in sand dune habitat, south-western Queensland. Wildl. Res. 25, 11-22.

McCafferty, D.J., 2007. The value of infrared thermography for research on mammals: previous applications and future directions. Mammal Rev. 37, 207-223.

Meek, P.D., Ballard, G., Fleming, P.J.S., 2012. An Introduction to Camera Trapping for Wildlife Surveys in Australia. PestSmart Toolkit publication, Invasive Animals Cooperative Research Centre, Canberra, Australia.

Menkens, G.E.J.R., Biggins, D.E., Anderson, S.H., 1990. Visual counts as an index of whitetailed prairie dog density. Wildl. Soc. Bull. 18, 290-296.

Mitchell, B., Balogh, S., 2007. Monitoring techniques for vertebrate pests: wild dogs. NSW Department of Primary Industries, Bureau of Rural Sciences.

Molenberghs, G., Verbeke, G., Demetrio, C.G., 2007. An extended random-effects approach to modeling repeated, overdispersed count data. Lifetime Data Anal. 13 (4), 513-531. http://dx.doi.org/10.1007/s10985-007-9064-y. 
Pinheiro, J., Bates, D., DebRoy, S., Sarkar, D., Core Team, R., 2015. nlme: linear and nonliear mixed effect models. R package version Vol. 3, pp. 1-119 (http://CRAN.R-project.org/ package $=$ nlme).

Pollock, K.H., 1995. The challenges of measuring change in wildlife populations: biometrician's perspective. In: Grigg, G.C., Hale, P.T., Lunney, D. (Eds.), Conservation Through the Sustainable Use of Wildlife Centre for Conservation Biology. The University of Queensland, pp. 117-121.

Powell, K.L., Robel, R.J., Kemp, K.E., Nellis, M.D., 1994. Above ground counts of black-tailed prairie dogs: temporal nature and relationship to burrow entrance density. J. Wildl. Manag. 58, 361-366.

Putman, R.J., 1984. Facts from faeces. Mammal Rev. 14, 79-97.

Reid, V.H., Hansen, R.M., Ward, R.L., 1966. Counting mounds and earth plugs to census mountain pocket gophers. J. Wildl. Manag. 30, 327-334.

Robbins, C.S., Bystrack, D., Geissler, P.H., 1986. The breeding bird survey: its first fifteen years, 1965 1979. USDI, Fish and Wildlife Service Research Publication 157, Washington, D.C.
Servoss, W., Engeman, R.M., Fairaizl, S., Cummings, J.L., Groninger, N.P., 2000. Wildlife hazard assessment at Phoenix Sky Harbor International Airport. Int. Biodeterior. Biodegrad. 45, 111-127.

Stoddart, L.C., Griffiths, R.E., Knowlton, F.F., 2001. Coyote responses to changing jackrabbit abundance affect sheep predation. J. Range Manag. 54, 15-20.

Sutherland, W.J., 1996. Ecological Census Techniques. Cambridge University Press, Cambridge, UK.

Twigg, L.E., Lowe, T.J., Gray, G.S., Martin, G.R., Wheeler, A.G., Barker, W., 1998. Spotlight counts, site fidelity and migration of European rabbits (Oryctolagus cuniculus). Wildl. Res. 25, 113-122.

U.S. Fish and Wildlife Service, 2000. Environmental Assessment for the Management of Predation Losses to Sea Turtle Nests at the Hobe Sound National Wildlife Refuge, Martin County, Florida. U.S. Fish and Wildlife Service, Hobe Sound, Florida, USA.

Whisson, D.A., Engeman, R.M., Collins, K., 2005. Developing relative abundance techniques (RATS) for monitoring rodent populations. Wildl. Res. 32, 239-244. 